\title{
Thermal Stability and Magnetic Property of Ni-Co-P Hollow Microfibers Prepared by Electroless Plating
}

\author{
Hirokazu Oda, Tomohiro Shimazu, Tomokazu lyoda and Masaru Nakagawa* \\ Chemical Resources Laboratory, Tokyo Institute of Technology \\ 4259 Nagatsuta, Midori-ku, Yokohama 226-8503, Japan \\ Fax: +81-45-924-5247, e-mail: nakagawa.m.aa@m.titech.ac.jp
}

\begin{abstract}
Temary nickel-cobalt-phosphorus (Ni-Co-P) hollow microfibers could be prepared by electroless deposition on a hydrogen-bonded supramolecular aggregate as a fibrous template, followed by annealing at $600^{\circ} \mathrm{C}$ under an argon atmosphere. Their chemical composition, crystallinity, magnetic property and morphology were characterized. The cobalt content in the hollow microfibers could be tuned simply by a choice of an electroless plating bath, mainly composed of $\mathrm{NiSO}_{4}$ and $\mathrm{CoSO}_{4}$ as metal sources and $\mathrm{NaH}_{2} \mathrm{PO}_{2}$ as a reducing reagent and containing different cobalt content expressed as $\left[\mathrm{Co}^{2+}\right] /\left(\left[\mathrm{Ni}^{2+}\right]+\left[\mathrm{Co}^{2+}\right]\right)$. The Ni-P hollow microfiber without cobalt showed ferromagnetism with a small coercive force, while saturated magnetization, residual magnetization and coercive force of the $\mathrm{Ni}-\mathrm{Co}-\mathrm{P}$ hollow microfibers decreased significantly with an increase of the cobalt content. The increase of the cobalt content induced simultaneously an increase of the phosphorus content, so that crystallization temperature to form a ferromagnetic f.c.c nickel phase was increased and thermal stability of the hollow structure could be improved.

Key words: hollow microfiber, electroless deposition, magnetic property, nickel, cobalt
\end{abstract}

\section{NNTRODUCTION}

Organic, inorganic and metallic hollow microfibers with a pore diameter of less than a micrometer have attracted much attention because of the prospects of their unique physical and chemical properties. If Template synthesis is widely accepted as a simple, high-throughput, and cost-effective method for preparing such hollow microfibers. We have recently demonstrated that hydrogen-bonded fibrous supramolecular aggregates of amphoteric azopyridine carboxylic acids are available to morphology-tunable and recyclable advanced templates for preparing nickel-phosphorus (Ni-P) hollow microfibers by electroless deposition with palladium chloride. $\left.{ }^{[2}, 3\right]$ Ni-P hollow microfibers annealed under an inert gas atmosphere showed ferromagnetism ${ }^{[4]}$

In this study, we imvestigated a method for preparing nickel-cobalt-phosphorus (Ni-Co-P) ternary hollow microfibers by electroless deposition and for tuning their magnetic properties such as saturated magnetization, residual magnetization, and coercive force simply by cobalt content It is anticipated that uniaxial orientation of the magnetic hollow microfiber under an magnetic field ${ }^{[4]}$ will be affected by its magnetic properties. Here, annealed $\mathrm{Ni}-\mathrm{Co}-\mathrm{P}$ hollow microfibers with different cobalt content were characterized by inductively coupled plasma atomic emission spectrometer (ICP-AES), X-ray diffractometer and vibrating sample magnetometer (VSM) measurements, and scaming electron microscope (SEM) and transmission electron microscope (TEM) observations.

\section{EXPERTMENT}

2-1. Material

A fibrous supramolecular aggregate formed from 6-[2-propy]-4-(4-pyridylazo)phenoxy]hexanoic acid was used in this study, and its preparation was detailed in our previous paper. ${ }^{[3} \mathrm{PdCl}_{2}$ was purchased from Aldrich. Deionized water was used thoroughly. Other chemicals were of reagent grade, purchased from Kanto Chemicals, Ltd., Japan, and used as received.

\section{2-2, Preparation of Ni-Co-P hollow microfiber}

The fibrous supramolecular aggregate prepared in an aqueous solution according to our previous pape ${ }^{[3]}$ was filtered and rinsed with deionized water. A rinsed fibrous molecnlar aggregate was dispersed in an $\mathrm{HCl}$-acidic aqueous solution of $\mathrm{pH} 2.5$ containing 1.0 mmol dm $\mathrm{PdCl}_{2}$ and agitated at room temperature for $24 \mathrm{~h} . \mathrm{A} \mathrm{PdCl}_{2}$-treated fibrous molecular aggregate was filtered and immersed at $30^{\circ} \mathrm{C}$ for $1 \mathrm{~h}$ in a Ni-P electroless plating bath consisting of $0.050 \mathrm{~mol} \mathrm{dm}^{-3}$ $\mathrm{Ni}\left(\mathrm{H}_{2} \mathrm{PO}_{2}\right)_{2} \cdot 6 \mathrm{H}_{2} \mathrm{O}, 0.19 \mathrm{~mol} \mathrm{dm}^{-3} \mathrm{H}_{3} \mathrm{BO}_{3}, 0.030 \mathrm{~mol}$ $\mathrm{dm}^{-3} \mathrm{CH}_{3} \mathrm{COONa}$ and $9.8 \mathrm{mmol} \mathrm{dm}^{-3}\left(\mathrm{NH}_{4}\right)_{2} \mathrm{SO}_{4}{ }^{[3]}$ An activated fibrous molecular aggregate was filtered and dispersed again at $30^{\circ} \mathrm{C}$ for $24 \mathrm{~h}$ in six kinds of Ni-Co-P electroless plating baths containing a different cobalt concentration [ $\left.\mathrm{CO}^{2+}\right]$. A pH value of the bath was adjusted to 5.5 by adding a dilute aqueous ammonia solution. The composition of the electroless plating baths was summarized in Table 1.

The fibrous template plated with a Ni-Co-P alloy was filtered, washed with deionized water, and immersed in 2-butanol for $24 \mathrm{~h}$ to remove the organic supramolecular template. After collecting by filtration and dying, a Nj-Co-P bollow microfiber was annealed at a different temperature in the range of $400-800^{\circ} \mathrm{C}$ under an argon atmosphere for $1 \mathrm{~h}$. Annealed Ni-Co-P hollow microfibers were obtained in a powder state. 
Table 1. Chemical composition of Ni-Co-P electroless plating baths

\begin{tabular}{ll}
\hline Reagent & Concentration $/ \mathrm{mmol} \mathrm{dm}^{-3}$ \\
\hline $\mathrm{NiSO}_{4} \cdot 6 \mathrm{H}_{2} \mathrm{O}$ & $50-\mathrm{x}$ \\
$\mathrm{CoSO} \mathrm{H}_{4} \cdot 7 \mathrm{H}_{2} \mathrm{O}$ & $\mathrm{x}=0,5,10,15,20$, and 25 \\
$\mathrm{Na}_{2} \mathrm{H}_{2} \mathrm{PO}_{2} \cdot \mathrm{H}_{2} \mathrm{O}$ & 100 \\
$\mathrm{H}_{3} \mathrm{BO}_{3}$ & 190 \\
$\mathrm{CH}_{3} \mathrm{COONa}_{2}$ & 30 \\
$\left(\mathrm{NH}_{4}\right)_{2} \mathrm{SO}_{4}$ & 9.8 \\
\hline
\end{tabular}

\section{2-3. Characterization}

A chemical composition was analyzed with a Shimadan ICP-8100 ICP-AES. An X-ray diffraction (XRD) pattern was measured with a Rigaku Rimt-Ultima diffractometer. A magnetic property at room temperature was investigated using a Toei Industry VSM-C7 magnetometer. A SEM image was taken with a Hitachi S-3000N microscope. A TEM image was taken with a Hitachi H-7100 microscope.

\section{RESULTS AND DISCUSSION}

\section{3-1. Control of the cobalt content}

Electroless deposition of a Ni-Co-P alloy on the $\mathrm{PdCl}_{2}$-treated fibrous molecular aggregate was hardly brought about in the electroless plating baths containing $\mathrm{CoSO}_{4}$, while electroless deposition of a Ni-P alloy proceeded without $\mathrm{CoSO}_{4}$. It was found during trials and errors that Ni-Co-P electroless deposition took place on a $\mathrm{PdCl}_{2}$-treated fibrous molecular aggregate after short immersion in the Ni-P electroless plating bath. The event indicated that $\mathrm{Co}^{2+}$ species in the bath was not reduced directly by reducing reagent $\mathrm{H}_{2} \mathrm{PO}_{2}{ }^{-}$and that metal cobalt deposition was induced by a replacement reaction of the $\mathrm{CO}^{2+}$ species with metal nickel formed beforehand by the reducing reagent The two-step

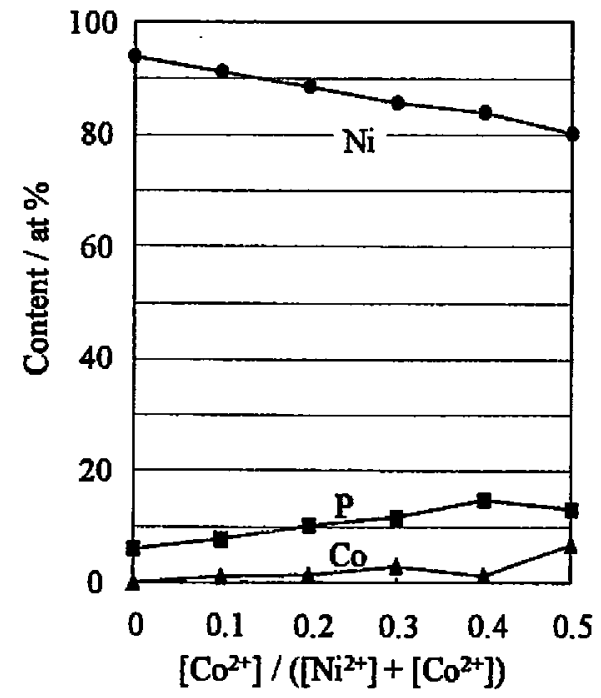

Figure 1. Chemical composition of $\mathrm{N}-\mathrm{Co}-\mathrm{P}$ hollow microfibers as a function of $\left[\mathrm{Co}^{2+}\right] /\left(\left[\mathrm{Ni}^{2+}\right]+\left[\mathrm{Co}^{2+}\right]\right)$.

electroless deposition allowed us to prepare Ni-Co-P ternary hollow microfibers in a manner similar to the method for preparing a Ni-P hollow microfiber. ${ }^{[3]}$
Six kinds of Ni-Co-P electroless plating baths comtaining different concentration of $\mathrm{CoSO}_{4}(0,5,10,15$, 20 and $25 \mathrm{mmol} \mathrm{dm}^{-3}$ ) were prepared, to tune a chemical composition of a Ni-Co-P hollow microfiber. The sum of $\mathrm{NiSO}_{4}$ and $\mathrm{COSO}_{4}$ concentration was constant 50 mmol d m${ }^{-3}$, becanse a difference of iomic strength in the plating baths was ignored. Here, the ratio of the $\mathrm{CoSO}_{4}$ concentration in the baths was expressed as $\left[\mathrm{Co}^{2+}\right] /\left(\left[\mathrm{Ni}^{2+}\right]+\left[\mathrm{Co}^{2+}\right]\right)$. Figure 1 shows the chemical composition of the $\mathrm{Ni}-\mathrm{C} 0-\mathrm{P}$ hollow microfibers prepared from the six electroless plating baths. The chemical composition was determined by ICP-AES. The $x$ axis is $\left.\left[\mathrm{Co}^{2+}\right] /\left(\mathrm{Ni}^{2+}\right]+\left[\mathrm{Co}^{2+}\right]\right)$. The $y$ axis is on a scale of atomic \%. The cobalt content in the hollow microfibers was increased concomitantly with the $P$ content, as the ratio of $\left[\mathrm{CO}^{2+}\right]$ in the baths was increased. The ratio of nickel to phosphorus in the hollow microfibers decreased with an increase of the ratio of $\left[\mathrm{Co}^{2+}\right]$. It was found that the cobalt content in the Ni-Co-P hollow microfibers could be simply tuned by the ratio of $\left[\mathrm{CO}^{2+}\right]$ in the electroless plating baths.

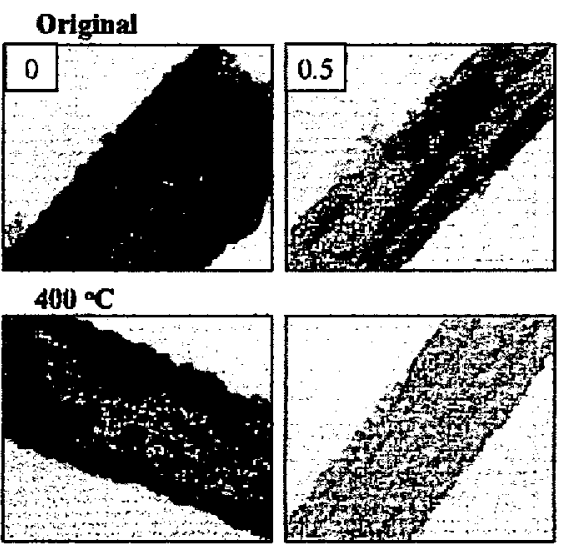

$500{ }^{\circ} \mathbf{C}$
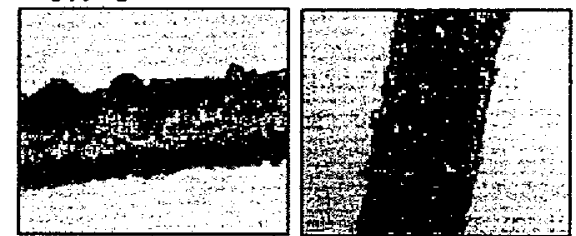

$600 \times \mathrm{C}$
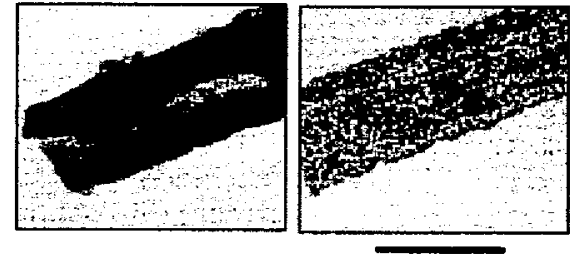

Scale bar : $500 \mathrm{~nm}$

Figure 2. TEM images of Ni-P hollow microfibers (left column) and $\mathrm{Nj}-\mathrm{Co}-\mathrm{P}$ hollow microfibers (right column) before and after annealing at 400,500 and $600{ }^{\circ} \mathrm{C}$ under an argon atmosphere for $1 \mathrm{~h}$. The Ni-Co-P hollow microfiber was prepared from the plating bath containing the $\left[\mathrm{Co}^{2+}\right]$ ratio of 0.5 . 


\section{3-2. Thermal stability}

Figure 2 shows TEM images of Ni-P hollow microfibers (left column) and $\mathrm{Ni}-\mathrm{Co}-\mathrm{P}$ hollow microfibers (right column) before and after annealing at 400,500 , and $600{ }^{\circ} \mathrm{C}$. The annealing was carried out under an argon atmosphere for $1 \mathrm{~h}$. As-prepared original $\mathrm{Ni}-\mathrm{Co}-\mathrm{P}$ hollow microfibers before annealing had an outer diameter of approximately $0.5 \mu \mathrm{m}$ and a wall thickness of $50-100 \mathrm{~nm}$ irrespectively of the ratio of $\left[\mathrm{Co}^{2+}\right]$ in the electroless plating baths. All of the Ni-Co-P hollow microfibers were composed of nanoparticles of $10-20 \mathrm{~mm}$ in diameter. Annealing under an argon atmosphere was carried out to avoid forming metal oxides. In the case of the Ni-P hollow microfiber prepared from the electroless plating bath containing $\left[\mathrm{Co}^{2+}\right]=0$, fused and enlarged nanoparticles were observed after annealing at higher than $500^{\circ} \mathrm{C}$. Most of the nanoparticles were fused at $600^{\circ} \mathrm{C}$.

On the other hand, although the Ni-Co-P hollow microfiber prepared from the bath containing the $\left[\mathrm{Co}^{2+}\right]$ ratio of 0.5 was annealed at $600^{\circ} \mathrm{C}$, there was not any significant morphological change. Nanoparticles of a $\mathrm{Ni}-\mathrm{CO}-\mathrm{P}$ alloy were partially fused at $700^{\circ} \mathrm{C}$, and hollow structure of the microfibers disappeared after annealing at $800{ }^{\circ} \mathrm{C}$. The TEM observations indicated obviously that the $\mathrm{Ni}-\mathrm{Co}-\mathrm{P}$ hollow microfibers were thermally stable than the Ni-P hollow microfiber.

\section{3-3. Thermally induced crystallization}

A nickel-phosphorus film prepared a Ni-P electroless deposition on a solid substrate surface, in general, shows an amorphous phase. ${ }^{[5]}$ The amorphous Ni-P alloy is transformed to a f.c.c nickel phase and several crystalline phases containing phosphorus and nickel by heating. Here, we investigated what crystalline phase appeared in the $\mathrm{Ni}-\mathrm{Co}-\mathrm{P}$ hollow microfibers after annealing by XRD measurement.

Figure 3 indicates XRD patterns of Ni-Co-P hollow microfibers before and after annealing at 400,500 , and $600{ }^{\circ} \mathrm{C}$ under an argon atmosphere for $1 \mathrm{~h}$, with results for the microfibers prepared from the plating bath without $\mathrm{CoSO}_{4}$ and with $\mathrm{CoSO}_{4}$ at the $\left[\mathrm{CO}^{2+}\right]$ ratio of 0.5 shown in left and right of Figure 3, respectively. The Ni-Co-P hollow microfiber prepared from the bath without $\mathrm{CoSO}_{4}$ corresponds to the Ni-P hollow microfiber. The Ni-P hollow microfiber before annealing exhibited a broad peak at $2 \theta=45^{\circ}$, which indicates that nanoparticles composing the Ni-P hollow microfiber were in an amorphous phase. Several diffraction peaks were observed after annealing at 400 ${ }^{\circ} \mathrm{C}$. The diffraction peaks sharpened significantly at $600{ }^{\circ} \mathrm{C}$. As seen in Figure 2 indicating TEM images of the Ni-P microfibers, nanoparticles composing the microfiber were fused at $600{ }^{\circ} \mathrm{C}$. The fusion of the nanoparticles caused obviously the crystallization from an amorphous phase. It was found from the diffraction pattern that f.c.c. nickel and $\mathrm{Ni}_{3} \mathrm{P}$ crystalline phases ${ }^{[5]}$ were formed by annealing at $600^{\circ} \mathrm{C}$.

In the case of the Ni-Co-P hollow microfiber, the XRD pattern also indicated that nanoparticles composing the microfiber were in an amorphous phase. Similarty to the Ni-P microfiber, indefinable diffraction peaks appeared after annealing at $400{ }^{\circ} \mathrm{C}$. However, diffraction peaks were hardly changed even after annealing at $600{ }^{\circ} \mathrm{C}$. The indefinable diffraction peaks suggested that $\mathrm{Ni}_{3} \mathrm{P}, \mathrm{Ni}_{12} \mathrm{P}_{5}$ and $\mathrm{Ni}_{5} \mathrm{P}_{2}$ crystalline phases were formed. As seen in Figure 2 indicating TEM images of the Ni-Co-P hollow microfibers, the shapes of nanoparticles were maintained even after annealing at $600^{\circ} \mathrm{C}$. Taking account of the facts, we anticipated that the phosphorus-rich crystalline phases were formed in the nanoparticles. The increase of the cobalt and

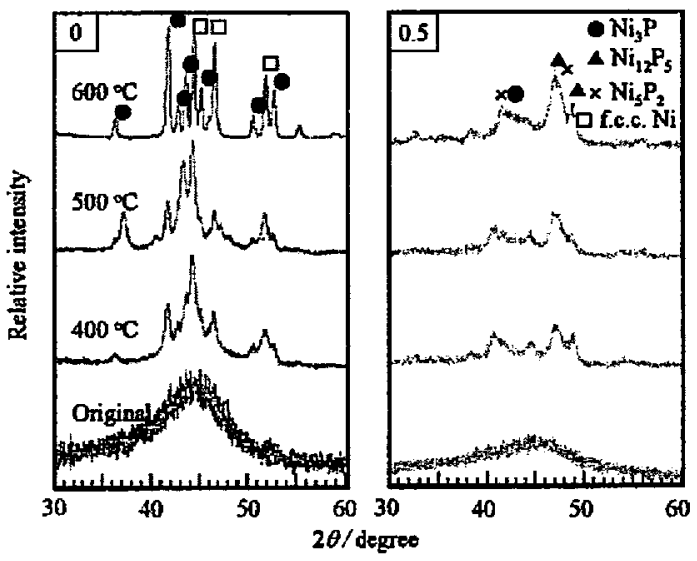

Figure 3. XRD patterns of Ni-Co-P hollow microfibers prepared from the plating baths containing $\mathrm{CoSO}_{4}$ at the $\left[\mathrm{Co}^{2+}\right]$ ratio of 0 and 0.5 . As-prepared original hollow microfibers were annealed at 400,500 , and $600^{\circ} \mathrm{C}$ under an argon atmosphere for $1 \mathrm{~h}$.

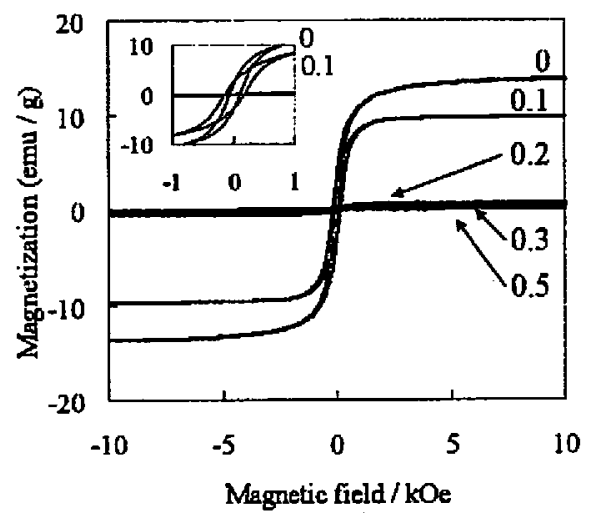

Figure 4. Hysteresis loops of Ni-Co-P hollow microfibers prepared from the plating baths containing $\mathrm{CoSO}_{4}$ at the $\left[\mathrm{Co}^{2+}\right]$ ratio of $0,0.1$, $0.2,0.3$ and 0.5 , which were annealed at 600 ${ }^{\circ} \mathrm{C}$ under an argon atmosphere for $1 \mathrm{~h}$.

phosphorus contents in the Ni-Co-P hollow microfibers suppressed the formation of an f.c.c. nickel phase showing ferromagnetism.

\section{3-4. Magnetic property of Ni-Co-P hollow microfibers}

The magnetic property of the Ni-Co-P hollow microfibers was measured with a vibrating sample magnetometer (VSM) at rom temperature around $20^{\circ} \mathrm{C}$. 
Figure 4 indicates hysteresis loops of the Ni-Co-P hollow microfibers annealed at $600{ }^{\circ} \mathrm{C}$. The Ni-P hollow microfiber prepared without $\mathrm{CoSO}_{4}$ exhibited a saturated magnetization of $12.6 \mathrm{emu} \mathrm{g}^{-1}$ and a coercive force of $116 \mathrm{Oe}$. In the case of the Ni-Co-P hollow microfiber prepared from the bath at the $\left[\mathrm{Co}^{2+}\right]$ ratio of 0.1 , the saturated magnetization was $9.75 \mathrm{emu}^{-1}$, and the coercive force was $154 \mathrm{Oe}$. Interestingly, the $\mathrm{Ni}-\mathrm{Co}-\mathrm{P}$ hollow microfibers prepared at the $\left[\mathrm{Co}^{2+}\right]$ ratio of 0.3 and 0.5 did not show a hysteresis loop characteristic of ferromagnetic materials. Saturated magnetization, residual magnetization, and coercive force of the Ni-Co-P were plated as a function of $\left[\mathrm{Co}^{2+}\right] /\left(\left[\mathrm{Ni}^{2+}\right]+\left[\mathrm{Co}^{2+}\right]\right)$ in Figure 5. The results for the saturation magnetization, the residual magnetization, and the coercive force were shown in top, middle and bottom parts of Figure 5, respectively. It was found that the Ni-Co-P hollow microfibers prepared at the $\left[\mathrm{Co}^{2+}\right]$ ratio of lower than 0.2 showed ferromagnetism after annealing at $600{ }^{\circ} \mathrm{C}$. The events come from suppressing the formation of an f.c.c. nickel phase due to the increase of the cobalt and phosphorus contents.
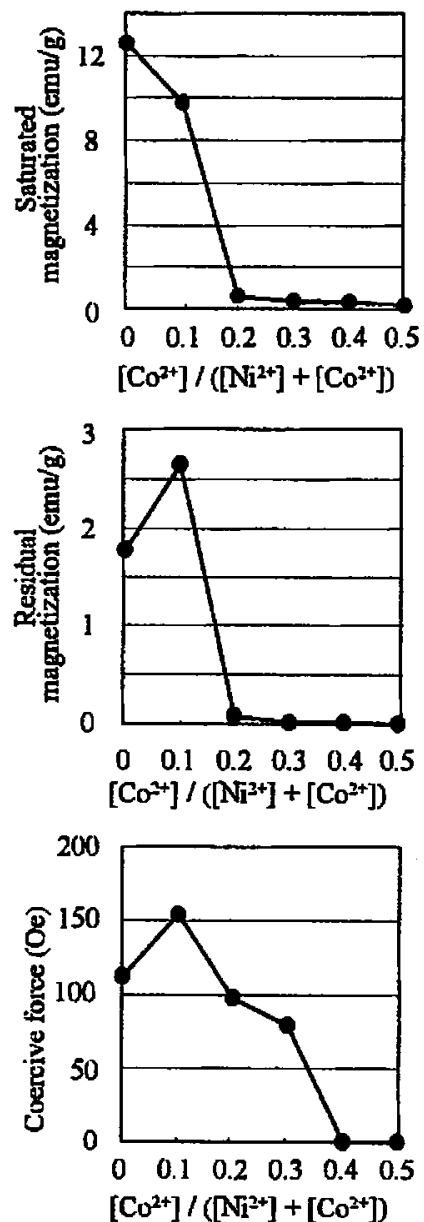

Figure 5. Saturated magnetization (top) residual force (middle), and coercive force (bottom) of the $\mathrm{Ni}-\mathrm{Co}-\mathrm{P}$ hollow microfibers annealed at $600{ }^{\circ} \mathrm{C}$ as a function of $\left[\mathrm{Co}^{2+}\right] /\left(\left[\mathrm{Ni}^{2+}\right]+\left[\mathrm{Co}^{2+}\right]\right)$ in electroless plating baths.

\section{CONCLUSION}

We could prepare nickel-cobalt-phosphorus (NiCo-P) temary hollow microfibers by a template synthesis with a hydrogen-bonded fibrous molecular aggregate in electroless deposition. The chemical composition could be tuned simply by changing the cobalt content in electroless plating baths containing $\mathrm{NiSO}_{4}$ and $\mathrm{CoSO}_{4}$ as metal sources and $\mathrm{NaH}_{2} \mathrm{PO}_{2}$ as a reducing reagent The increase of the cobalt content in the Ni-Co-P hollow microfibers induced simultaneously an increase of the phosphorus content. The cobalt obviously suppressed the formation of an f.c.c. nickel phase showing ferromagnetism and improved thermal stability of hollow structure.

\section{REFERENCES}

[1] Y. Xia and P. Yang, Adv. Mater., 15, 351 (2003).

[2] M. Nakagawa, D. Ishii, K. Aoki, T. Seki, and T. Iy oda, Adv. Mater., 17, 200 (2005).

[3] D. Ishii, T. Nagashima, M. Udatsu, R.-D. Sun, Y. Ishikawa, S. Kawasaki, M. Yamada, T. Iyoda, and $M$. Nakagawa, Chem Mater., 18, 2152 (2006).

[4] M. Nakagawa, D. Ishii, and T. Nagashima, Kagaku-to-Kogyo (Japanese), 58, 494 (2005).

[5] Y.-L. Tai and H. Teng, Chem. Mater., 16, 338 (2004).

(Received December 10, 2006;Accepted March 8, 2007) 